\title{
Addressing Diversity on College Campuses: Changing Expectations and Practices in Instructional Leadership
}

\author{
Angela Chen ${ }^{1}$ \\ ${ }^{1}$ University of Hartford, West Hartford, Connecticut, United Stated \\ Correspondence: Angela Chen, University of Hartford, West Hartford, Connecticut, United Stated. E-mail: \\ YACHEN@hartford.edu
}

Received: February 21, 2017

Accepted: March 6, 2017

Online Published: March 27, 2017

doi:10.5539/hes.v7n2p17

URL: http://doi.org/10.5539/hes.v7n2p17

\begin{abstract}
The increasing diversity evident across all facets of American society is creating opportunities as well as challenges for instructional leaders across the nation's postsecondary institutions. Racial and ethnic diversity and the attendant challenges and benefits of multiculturalism in society are more awareness in higher education. This study synthesizes the issues of Diversity in Higher Education Institutions and ethnically diverse university environments in a U.S. context and effective practices in Instructional Leadership based on that work to help administrators to find an effective way for future practice. In this way, the expected outcome is the creation of opportunities for underrepresented minorities so that all students can reach their greatest potential.
\end{abstract}

Keywords: racial/ethnic diversity, culture, multiculturalism, minority, campus climate, higher education, instructional leadership

\section{Introduction}

The increasing diversity evident across all facets of American society is creating opportunities as well as challenges for instructional leaders across the nation's postsecondary institutions. The need to educate students in an environment that reflects the diversity of the country and the global society in which tomorrow's college graduates will be living and working is paramount. Research supports that a diverse campus environment is necessary to equip students to be successful in the 21st century and beyond (Milem, Chang, \& Antonio, 2005). How best to design and implement diversity initiatives, programs, and practices in our nation's colleges and universities so all students are supported and successful remains a question researchers, educators, and policymakers are currently trying to answer.

In today's institutions of higher learning, diversity is considered a transformative tool that aligns with the mission of postsecondary institutions to contribute to the betterment of society. However, institutionalizing diversity should be viewed as an ongoing process rather than a single action or outcome (Milem et al., 2005) and requires the buy-in of all institutional stakeholders. As such, certain institutions are further along in their diversity efforts than others, and the process is neither linear nor uniform across institutions (Aguirre \& Martinez, 2003). As a result, minority students remain underrepresented, unsupported, and unsuccessful in too many postsecondary institutions in this country (Harper \& Hurtado, 2007; Milem et al., 2005). In addition, diversity is about more than just the student population. For instance, nearly $83 \%$ of lecturers in public higher education institutions in the United States are White (Turner, González, \& Wood, 2008). True diversity involves an institution-wide focus that considers students, faculty, administrators, and staff.

Over the past century, the U.S. population has consistently become more demographically diverse (Turner et al., 2008). Naturally, this increased diversity has had a tremendous impact on our nation's postsecondary institutions. Initial efforts to address diversity on college campuses focused on the number of admitted students from nonmainstream populations. Today, research has shown that diversity is much more nuanced and involves every individual and department associated with the institution of higher learning. In this paper, I aim to analyze instructional leadership in relation to diversity in higher education. I first review the research on how exclusionary practices affect minority (and majority) students' educational experiences. Then, the discussion focuses on how the drive for diversity is changing professional practice. It is in the hands of those in positions of instructional leadership to ensure that all students have access to and develop the social, intellectual, cultural, and emotional capabilities required in the 21 st century. 


\section{Issues of Diversity in Higher Education Institutions}

A lack of diversity within the university community limits the educational experiences available for students and compromises the ability of the institution to fulfill its mission (American Council on Education \& American Association of University Professors, 2000). Further exacerbating the situation, some diversity-related policies implemented by individual postsecondary institutions have been contested on the legal ground that they discriminate against White students. Such legal cases have made it all the way to the Supreme Court, and these Court decisions shape what those in positions of professional leadership can do on their campuses.

For example, in an effort to diversify the racial makeup of higher education institutions, U.S. policymakers and legislators enacted a social policy (affirmative action) to remedy the deleterious effects of discriminatory practices against racial and ethnic minorities (Aguirre \& Martinez, 2003). However, resistance to the implementation of affirmative action is a factor that currently contributes to the under representation of minorities in American universities. One juridical ruling that has been influential is the 2003 Supreme Court decision in Grutter v. Bollinger. In this case, the Court determined that ensuring student diversity in postsecondary institutions was convincing interest for using race as a factor in university admissions. The Court's decision was motivated by the need to prepare students for an increasingly diverse global society. Despite the decision being aimed at student admissions, it lends support to the diversity debate at other levels of institutional practice. Although affirmative action identifies one process through which institutions of higher learning can diversify their student body, the majority of institutions remain reluctant to utilize this policy due to the criticisms and public outcry surroundingit (Aguirre \& Martinez, 2003). Failure to systematically implement affirmative action policies contributes to the underrepresentation of minority students (Turner et al., 2008) and leaves institutions struggling for alternative means of creating inclusive educational environments.

As the population in the United States continues to become more diverse, the need for a workforce that can respond to these changing demographics is becoming more pressing (Smith \& Schonfeld, 2000). In response, postsecondary institutions, working with private- and public-sector partners, identify and prioritize the skill set their students must possess to be successful graduates and then distribute resources across their campuses so those priorities can be achieved. One such priority is a racially diverse student body (Gurin, 2002). A multicultural student body is often the first indicator to students that an institution is committed to diversity, but it alone is not a sufficient means of achieving a diverse institution (Smith \& Schonfeld, 2000). It is not enough to simply bring together a diverse group of students, although this is an important first step in creating opportunities for students to learn from diversity. Instructional leaders should be aware that minority students often have difficulty (or have no interest) in assimilating into the majority culture and may feel frustrated and isolated on their postsecondary campus (Weicheng, 2003). As such, formal opportunities for minority and majority students to interact with one another and learn from each other in various contexts is needed. Through informal feedback and formal program evaluation, it is possible to determine which of these programs and services are working for students and what students perceive to be their additional needs. Creating a welcoming campus climate involves a complex interaction of many elements, both academic and social in nature.

Early efforts to increase diversity on college campuses focused primarily on increasing minority student enrollment, with little thought about faculty and staff diversity. Demographic trends showed that $80 \%$ of the students likely to attend postsecondary education by 2015 would be nonmainstream students (Turner, 2002b). This reality beckons a need for increased faculty of color to be involved in the educational process. According to Turner et al. (2008), a diverse faculty is necessary in recruiting students of color to higher education because these students want to enroll in universities with diverse faculties so they are less likely to experience isolation. In addition, a diverse faculty contributes to the development of novel scholarship and approaches to teaching. Individuals from different cultural backgrounds bring with them new ways of thinking, researching, and writing. Although universities have engaged in diversity efforts, such as increasing faculty of color, evidence suggests that these efforts have fallen short. For example, faculty of color made up only $17 \%$ of all full-time faculty in 2005. Of this number, $7.5 \%$ were Asian, 5.5\% were African American, 3.5\% were Hispanic, and American Indians made up $0.5 \%$ (Turner et al., 2008). Furthermore, an examination of full professor rank showed that people of color comprised only $12 \%$ of the nation's college faculty (Turner et al., 2008). If we factor in gender, the percentage is even lower since higher education faculty remain dominated by a male majority. According to 2008 data, only a small percentage of higher education faculty were females of color: $1 \%$ of female faculty were Asian, $1 \%$ were Black, $0.6 \%$ were Hispanic, and $0.1 \%$ were American Indian (Turner et al., 2008).

A diverse faculty enhances the quality of the educational experience and is necessary to ensure that new ideas and approaches to teaching are included (Turner, 2002a). Anthony Antonio (2004) considered the pedagogical approach of faculty of color and their focus as they provided classroom instruction for students. He found 
underrepresented faculty emphasized social development associated with respect for others and prompted students to consider the societal issues connected with what is right and wrong. Faculty of color also were found to value and include co-curricular experiences to help actualize their curriculum. A correlation was identified between these values and the faculty's explicit desire to provide an education that would influence systemic change; as such, students were encouraged to be civically engaged and to use their classroom experiences to impact society.

Recruiting and retaining faculty of color continues to be a major concern for institutions of higher education. As was evidenced with minority students, just increasing the number of minority faculty on campus is not sufficient to result in systemic change. Of significance is the identification by minority faculty of a hostile campus climate and its impact on their professional and personal lives. Underrepresented faculty expressed concerns about how their service to their university community was formally evaluated and believed that the lack of recognition they received for their academic and personal work ultimately compromised their ability to progress through the tenure process. In addition, the feeling of being tokenized contributed to a hostile work climate and was not conducive to the recruitment or retention of faculty of color (Aguirre \& Martinez, 2003).

These current issues in diversity influence America's higher education system. Institutions can be proactive in fostering the educational benefits of diversity in the classroom and across campus by developing policies that address the issues outlined above. A university's goals for student education should include personal development and growth; new perspectives from people of diverse races, ethnicities, and cultures; and individual commitment to community and society. The following section describes instructional leadership practices that have been shown to be effective in terms of promoting diversity across postsecondary institutions.

\section{Effective Practices in Instructional Leadership}

Diversity in higher education informs instructional leadership. Professional practice in the area of diversity is guided by standards that define the roles of the higher education institution and the ideal relationship between higher education and diverse communities. The three standards that inform professional practice in instructional leadership in relation to diversity are as follows: (a) developing trust and engaging individual cultures, (b) developing new admissions and hiring policies, and (c) introducing diversity into the university through a systemic approach.

Developing trust and engaging individual cultures, which serve to restore the integrity of nonmainstream populations, are challenging tasks considering the lack of diversity in colleges and universities. The problem is that racial/ethnic minorities will find it difficult to believe that colleges and universities are looking after nonmainstream students' pecific interests if academic institutions have not transitioned into diverse academes. Nevertheless, developing trust is important when it comes to professional practice because instructional leadership necessitates partnership with communities, including diverse populations. Without trust, it will be difficult, if not impossible, for both parties to work together toward inclusiveness in the academe.

Instructional leadership then must focus on nurturing trust within the learning environment. Instructors may aim to achieve this objective through the development of new pedagogical approaches and the institution of teaching competencies in which their performance is evaluated based on how they nurture positive relationships with their students. Furthermore, it is necessary for instructors, staff, and administrators to undergo training in cultural competence, especially for White educators who may have limited knowledge and awareness of diversity. Instructors must serve as role models of tolerance, cultural awareness, and inclusive education not only for students but for their colleagues as well. Inviting faculty of color to the leadership table and engaging them in leadership roles will bolster diversity initiatives and encourage participatory leadership (Aguirre \& Martinez, 2003). Colleges and universities that are dedicated to advancing diversity as an institutionalized value must consider faculty of color as more than a tool, strategy, or demographic number. Hence, instructors must aim to address diversity by nurturing equality and cultural competence in the academe and developing trust to establish a helpful and supportive learning environment for all students.

Effective diversity initiatives include the development of new admissions and hiring policies that promote equal opportunity and equality. Enhancing the compositional diversity of an institution is achieved through increasing the proportional representation of racial and ethnic minorities. In addition, institutional policies that increase the compositional diversity of an institution indicate that diversity is highly valued by the institution and its leaders (Milem et al., 2005). The implementation of effective human resources strategies that increase recruitment and retention rates of faculty of color is also essential for maximizing both human and institutional capital (Turner et al., 2008). However, diversifying university faculty should not be the responsibility of instructional leaders alone. Training and increasing the knowledge of campus staff and faculty on the topic of diversity is an institutional 
effort that can help instructional leaders to achieve their mandate of diversifying university faculty. Additionally, aligning diversity at all levels of the institution is also critical. Diversity should focus on all departments of an institution, including support staff. Finally, in order to promote diversity and equal opportunity, institutions of higher education can adopt a formal policy similar to the University of California's Academic Personnel Policy that supports the appointment, tenure, and promotion of underrepresented faculty (Turner et al., 2008).

Introducing diversity into the university from a systemic approach has the propensity to challenge the historical understanding of power and equity and is necessary as colleges and universities prepare their students for the global society of the 21 st century. Aguirre and Martinez (2003) used two frameworks to demonstrate the interrelationship between diversity and institutions of higher education. Specifically, they considered the connection between the role of institutional leaders and the implementation of diversity in the academy. They concluded that the culture and environment of higher education impacts the advancement of diversity as a transformational element. Institutions that incorporate diversity into the framework of their organization are more likely to be successful in institutionalizing diversity as part of the overall culture. According to Milem et al. (2005), successful cultural change in a postsecondary institution must provide all students with the full range of educational benefits accrued through cross-racial interactions.

Today, colleges and universities are criticized for their preferential treatment of applicants and current students based on race and the presence of privilege systems wherein education and employment opportunities favor the privileged classes to the exclusion of underrepresented minorities. As diversity continues to grow in local school districts and force transition in postsecondary institutions, there is an increasing need for higher education institutions to accommodate diverse populations. Hence, instructional leaders need to openly challenge the inequities in academic institutions that disrupt and are detrimental to learning. They must also fight for social justice in favor of equity, which will inspire and inform others in the academic community to build cultural and racial tolerance and acceptance. They must also engage in conversations about gender, class, race, sexual orientation, immigration, and social justice. Instructional leaders are expected to incorporate diversity into their curricula in order to develop students' psychosocial, psychological, and social cognitive skills (Harper \& Hurtado, 2007; Milem et al., 2005). Finally, focusing on a systemic approach means that instructional leaders should view diversity as a positive social force that enhances student learning outcomes to facilitate cross-racial interactions.

\section{Recommendations for Future Practice}

I have analyzed and synthesized four different studies (i.e., Aguirre \& Martinez, 2003; Harper \& Hurtado, 2007; Milem et al., 2005; Turner et al., 2008) in order to make suggestions for professional practice that provide direction and support for institutional leaders fully committed to integrating diversity into their campus culture.

First, institutional leaders must lead a concerted effort to increase the number of diverse faculty, staff, and students on campus. At the institutional level, the role of instructional leadership should be recognized as central to the realization of diversity at institutions of higher learning. Instructional leadership is responsible for creating environments that are supportive and inclusive of all faculty, staff, and students so that they can maximize their institutional and human capital (Turner et al., 2008). Institutional leaders need to regularly connect with diverse faculty, staff, and student leadership to gain their support and learn more about the issues and concerns connected with the diversity experience. Institutional leaders are faced with many challenges when trying to embed diversity into the campus culture. Connecting with a wide variety of individuals and organizations is an important part of building support and avoiding resistance.

Second, institutional leaders must integrate diversity into the generalized curriculum of the institution. If institutional leaders are truly committed to enriching students' learning experiences, they must meaningfully engage in developing educational policies and teaching practices that foster diversity and are expected to incorporate diversity into their curriculum in order to develop students' psychosocial skills (Harper \& Hurtado, 2007; Milem et al., 2005). These efforts can create a better future for underrepresented and socially oppressed groups. This requires that every course include a focus on diversity. Institutional leaders must provide faculty development grants to enable faculty to retool their curriculum to include diversity and provide workshops and special educational sessions for faculty that include information about the value of incorporating diversity. Furthermore, institutional leaders must provide strategies for implementation and involve faculty in promoting diversity in the curriculum. Institutional leaders should be involved in providing rewards and recognition for administrators, faculty, and students who contribute to diversity in their fields. For example, attention to diversity in the curriculum and co-curriculum, particularly in the first 2 years of college, results in student development along many dimensions of complex thinking and social cognitive growth (Hurtado, 2005). 
All of the foregoing recommendations begin with leadership. If colleges and universities are to transition and diversify, then leadership must be prepared to lead. For this reason, instructional leadership is important. While leaders in government should ensure that existing education policies encourage diversification, the actual implementation of these policies in colleges and universities rests on instructional leaders. Instructional leaders must take it upon themselves to direct colleges and universities toward diversification. Since educators are instructional leaders, colleges and universities must make sure to diversify their faculty. Resolving diversity problems begins with this step. If institutions diversify their faculty, then there would be adequate instructional leaders to help in transitioning schools toward diversification. In addition, appropriate infrastructure must be provided to ensure diversity can be actualized. This should include funding, policy development, diversity-related offices, etc.

\section{Conclusion}

In an increasingly global world, diversification is highly necessary as a means to enable higher education institutions to accommodate learners and educators from various cultural backgrounds. Aside from accommodations and equal opportunities granted to racial/ethnic minorities, a diverse learning environment also improves learners' academic performance as proven by empirical evidence. On the contrary, lack of diversity in colleges and universities limits opportunities for both learners and educators. Faculty of color remain underrepresented due to prejudiced hiring, recruiting, and retention practices in these institutions. Furthermore, colleges and universities limit opportunities for faculty of color. The result of which is isolation and lack of opportunities for career growth and development. Minority learners, on the other hand, struggle to transition or perform well in the classroom due to loss of confidence, feelings of isolation, and inability to "fit in" the learning environment. Many racial minorities dropout of college or fail in class for these reasons.

Considering the struggles and problems brought about by racial segregation, prejudice, and discrimination, it is urgent that college and university leaders address these problems. Academic institutions are supposed to help learners achieve their goals and objectives in education and career development. Since the racial climate in learning environments affects student performance and the practice of educators, college and university leaders must adequately and consistently implement diversity efforts in all areas of their practice and throughout their institutions, including the recruitment, hiring, and retention of faculty of colorand the admission of a diverse student population. Furthermore, diversification must be consistent throughout all aspects of the academe, from the institution's philosophy to its mission statement, vision, policies, and standards.

Instructional leadership does not solely fall on instructors but rather on all stakeholders in the institutional community. Hence, instructional leadership involves the capacity to include all stakeholders in the community in creating a learning environment where people are aware of the effects of diversity on learning outcomes and actively contribute to cultural awareness, competence, and equity in all areas of learning. In this way, the expected outcome is the creation of opportunities for underrepresented minorities so that all students can reach their greatest potential.

\section{References}

Aguirre, A., \& Martinez, J. R. (2003). The diversity rationale in higher education: An overview of the contemporary legal context. Social Justice, 30(1), 138-152.

American Council on Education \& American Association of University Professors. (2000). Does diversity make a difference? Three research studies on diversity in college classrooms. Washington, DC: Author.

Antonio, A. L. (2004). When does race matter in college friendships? Exploring men's diverse and homogeneous friendship groups. Review of Higher Education, 27(4), 553-575. https://doi.org/10.1353/rhe.2004.0007

Gurin, P. (2002). New research on the benefits of diversity in college and beyond: An empiricalanalysis. Retrieved from http://www.diversityweb.org/digest/sp99/benefits.html

Harper, S. R., \& Hurtado, H. (2007). Nine themes in campus racial climates and implications for institutional transformation. New Directions for Student Services, 120, 7-24. https://doi.org/10.1002/ss.254

Hurtado, S. (2005). The next generation of diversity and intergroup relations research. Journal of Social Issues, 61(3), 595-610. https://doi.org/10.1111/j.1540-4560.2005.00422.x

Milem, F., Chang, M. J., \& Antonio, A. L. (2005). Making diversity work on campus: A research-based perspective. Retrieved from https://www.aacu.org/sites/default/files/files/

Smith, D. G., \& Schonfeld, N. B. (2000). The benefits of diversity: What the research tells us. About Campus, 5(5), 16-23. 
Turner, C. S. V. (2002a). Diversifying the faculty: A guidebook for search committees. Washington, DC: Association of American Colleges and Universities.

Turner, C. S. V. (2002b). Women of color in academe: Living with multiple marginality. Journal of Higher Education, 73, 74-93. https://doi.org/10.1353/jhe.2002.0013

Turner, C. S. V., González, J. C., \& Wood, J. L. (2008). Faculty of color in academe: What 20 years of literature tells us. Journal of Diversity in Higher Education, 1(3), 139-168. https://doi.org/10.1037/a0012837

Weicheng, Z. (2003). Bridging cultural differences in college selection and application: Incorporating college selection into a language curriculum for Chinese students. Journal of College Admissions, 180, 6-17.

\section{Copyrights}

Copyright for this article is retained by the author(s), with first publication rights granted to the journal.

This is an open-access article distributed under the terms and conditions of the Creative Commons Attribution license (http://creativecommons.org/licenses/by/4.0/). 